\title{
Multicenter Analysis of the SLC6A3/DATI VNTR Haplotype in Persistent ADHD Suggests Differential Involvement of the Gene in Childhood and Persistent ADHD
}

\begin{abstract}
Barbara Franke*, 1,2 , Alejandro Arias Vasquez ${ }^{1,2}$, Stefan Johansson ${ }^{3,4}$, Martine Hoogman², Jasmin Romanos ${ }^{5}$, Andrea Boreatti-Hümmer ${ }^{5}$, Monika Heine ${ }^{5}$, Christian P Jacob ${ }^{5}$, Klaus-Peter Lesch ${ }^{5,6}$, Miguel Casas $^{7,8}$, Marta Ribasés ${ }^{7}$, Rosa Bosch ${ }^{7}$, Cristina Sánchez-Mora ${ }^{7}$, Núria Gómez-Barros ${ }^{7}$, Noèlia Fernàndez-Castillo9, Mònica Bayés $^{10,11,12}$, Anne Halm $\varnothing y^{3}$, Helene Halleland ${ }^{13}$, Elisabeth T Landaas ${ }^{3,4}$, Ole B Fasmer ${ }^{14,15}$, Per M Knappskog ${ }^{4,15}$, Angelien JGAM Heister', Lambertus A Kiemeney ${ }^{16,22}$, JJ Sandra Kooij ${ }^{17}$, A Marije Boonstra ${ }^{17}$, Cees C Kan ${ }^{2}$, Philip Asherson ${ }^{18}$, Stephen V Faraone ${ }^{19}$, Jan K Buitelaar ${ }^{2}$, Jan Haavik ${ }^{3,14,23}$, Bru Cormand ${ }^{9,20,21,23}$, Josep Antoni Ramos-Quiroga ${ }^{7,8,23}$ and Andreas Reif ${ }^{5,6,23}$

'Department of Human Genetics, Radboud University Nijmegen Medical Centre, Nijmegen, The Netherlands; '2 Department of Psychiatry, Donders Institute for Brain, Cognition and Behavior, Centre for Neuroscience, Radboud University Nijmegen Medical Centre, Nijmegen, The Netherlands; ${ }^{3}$ Department of Biomedicine, University of Bergen, Bergen, Norway; ${ }^{4}$ Center for Medical Genetics and Molecular Medicine, Haukeland University Hospital, Bergen, Norway; ${ }^{5}$ Department of Psychiatry and Psychotherapy, Clinical and Molecular Psychobiology, University of Würzburg, Würzburg, Germany; ${ }^{6}$ Interdiciplinary Center for Clinical Research (IZKF), University of Würzburg, Würzburg, Germany; ${ }^{7}$ Department of Psychiatry, Hospital Universitari Vall d'Hebron, Barcelona, Catalonia, Spain; ${ }^{8}$ Department of Psychiatry and Legal Medicine, Universitat Autònoma de Barcelona, Catalonia, Spain; ' Departament de Genètica, Facultat de Biologia, Universitat de Barcelona, Catalonia, Spain; ${ }^{10}$ Genes and Disease Program, Center for Genomic Regulation (CRG), UPF, Barcelona, Catalonia, Spain; "'CIBER Epidemiología y Salud Pública, Instituto de Salud Carlos III (CRG), Barcelona, Catalonia, Spain; ' ${ }^{2}$ Centro Nacional de Genotipado (CeGen), Barcelona, Catalonia, Spain; ${ }^{13}$ Department of Biological and Medical Psychology, University of Bergen, Bergen, Norway; ${ }^{14}$ Department of Psychiatry, Haukeland University Hospital, Bergen, Norway; ${ }^{15}$ Department of Clinical Medicine, University of Bergen, Bergen, Norway; ${ }^{16}$ Department of Epidemiology and Biostatistics, Radboud University Nijmegen Medical Centre, Nijmegen, The Netherlands; ${ }^{17}$ PsyQ. Psycho-Medical Programs, Program Adult ADHD, The Hague, The Netherlands; ${ }^{18}$ MRC Social Genetic and Developmental Psychiatry, Institute of Psychiatry, Kings College London, London, UK; ${ }^{19}$ Departments of Psychiatry and Neuroscience and Physiology, SUNY Upstate Medical University, Syracuse, New York, USA; ${ }^{20}$ CIBER Enfermedades Raras, Instituto de Salud Carlos III, Barcelona, Catalonia, Spain; ${ }^{21}$ Institut de Biomedicina de la Universitat de Barcelona (IBUB), Catalonia, Spain
\end{abstract}

Attention deficit/hyperactivity disorder (ADHD) is one of the most common neuropsychiatric disorders with a worldwide prevalence around $4-5 \%$ in children and $1-4 \%$ in adults. Although ADHD is highly heritable and familial risk may contribute most strongly to the persistent form of the disorder, there are few studies on the genetics of ADHD in adults. In this paper, we present the first results of the International Multicentre Persistent ADHD Genetics CollaboraTion (IMpACT) that has been set up with the goal of performing research into the genetics of persistent ADHD. In this study, we carried out a combined analysis as well as a meta-analysis of the association of the SLC6A3/DATI gene with persistent ADHD in 1440 patients and 1769 controls from IMpACT and an earlier report. DATI, encoding the dopamine transporter, is one of the most frequently studied genes in ADHD, though results have been inconsistent. A variable number tandem repeat polymorphism (VNTR) in the $3^{\prime}$-untranslated region (UTR) of the gene and, more recently, a haplotype of this VNTR with another VNTR in intron 8 have been the target of most studies. Although the 10/10 genotype of the 3'-UTR VNTR and the I0-6 haplotype of the two VNTRs are thought to be risk factors for ADHD in children, we found the 9/9 genotype and the 9-6 haplotype associated with persistent ADHD. In conclusion, a differential association of DATI with ADHD in children and in adults might help explain the inconsistencies observed in earlier association studies. However, the data might also imply that DATI has a modulatory rather than causative role in ADHD. Neuropsychopharmacology (2010) 35, 656-664; doi:10.1038/npp.2009.170; published online 4 November 2009

Keywords: dopamine; transporters; psychiatry and behavioral sciences; neurogenetics

\footnotetext{
*Correspondence: Dr B Franke, Department of Human Genetics (855), Radboud University, Nijmegen Medical Centre, PO Box 9 I0I, 6500 HB Nijmegen, The Netherlands, Tel: + 310243610 I8I, Fax: + 310243616 658, E-mail: b.franke@antrg.umcn.nl

${ }^{22}$ Participating as representative of the Nijmegen Biomedical Study.

${ }^{23}$ These authors contributed equally to this work.

Received 3 April 2009; revised 5 August 2009; accepted 13 August 2009
} 


\section{INTRODUCTION}

Attention deficit/hyperactivity disorder (ADHD) is one of the most common neuropsychiatric disorders in children worldwide. The prevalence of the disorder in children is estimated to be $4-5 \%$ (Polanczyk et al, 2007). Although ADHD is classically considered a disorder of children and adolescents, only a subset of affected individuals remit (Faraone et al, 2000; Faraone et al, 2006), and the prevalence in adults lies between 1 and 4\% (Kessler et al, 2006; Polanczyk et al, 2007; Kooij et al, 2005). ADHD in adults causes a considerable burden to patients, their families, and society as a whole (Kessler et al, 2005a; Goodman, 2007; Bernfort et al, 2008). Adult patients have difficulties in social, educational, and professional fields, such as developing and maintaining stable social relationships, completing educational programs, and holding jobs.

Many twin and adoption studies have shown that ADHD symptoms in children are highly heritable, with about $76 \%$ contribution of heritable factors to phenotypic variance (Faraone et al, 2005). Although the heritability of the adult form of ADHD has not been formally established, the contribution of familial factors to this form of the disorder may be even larger than to childhood ADHD (Faraone, 2004). Numerous molecular genetic studies have been carried out to identify the genetic risk factors for ADHD. This has resulted in a limited number of significant and replicated findings, but all with modest effect sizes (for review see Faraone et al, 2005; Li et al, 2006) and explaining only a very small part of the genetic contribution to the disorder. Surprisingly, most molecular genetic studies report on children with ADHD, persistent ADHD has been largely neglected in genetics research so far.

In 2007, the International Multicentre Persistent ADHD CollaboraTion (IMpACT) was formed by researchers participating in the ADHD Molecular Genetics Network (Faraone, 2003; 2002). Currently, research groups from Germany, Norway, Spain, The Netherlands, the United Kingdom, and the United States participate in IMpACT. The collaboration was set up with the goal of performing and promoting research into the genetics of persistent ADHD. This publication presents its first results.

SLC6A3/DAT1, encoding the dopamine transporter, is probably the most studied gene in ADHD. The transporter is the direct target of stimulant-based medication effective in treating ADHD symptoms (Medori et al, 2008; Faraone et al, 2004). The polymorphism identified as a risk factor for $\mathrm{ADHD}$ is a variable number of tandem repeat (VNTR) in the 3 -untranslated region (UTR) of the gene. Since the original publication in 1995 (Cook et al, 1995), many studies have investigated the association of this VNTR with ADHD, with variable results. Meta-analyses of the data have also not been consistent, with the most comprehensive ones showing little or no significant effect (Maher et al, 2002; Faraone et al, 2005; Todd et al, 2005; Yang et al, 2007; Li et al, 2006). Because of the number of positive reports and because of significant evidence of heterogeneity between data sets, systematic differences between data sets might explain the apparent discrepancies (Li et al, 2006). Recently, two studies have suggested that a haplotype of two VNTRs in DAT1, including the $3^{\prime}$-UTR VNTR and a VNTR in intron 8 , is more strongly associated with ADHD than the $3^{\prime}$-UTR
VNTR alone (Asherson et al, 2007; Brookes et al, 2006). Recently, two studies also tested the involvement of the VNTR haplotype in persistent ADHD: whereas one of them did not find an association with the disorder (Bruggemann et al, 2007), the other concluded that the 9-6 haplotype, which differs from the 10-6 haplotype associated with childhood ADHD, has a role in the persistent disorder (Franke et al, 2008).

To resolve the apparent discrepancies in the literature, we performed a meta-analysis of published data and unpublished data from the IMpACT samples to further investigate the association between the DAT1 VNTR haplotype and persistent ADHD.

\section{MATERIALS AND METHODS}

The study reported here has been carried out in accordance with the Declaration of Helsinki.

\section{Patients and Controls, Assessment of Psychopathology at the IMpACT Nodes}

All patients were evaluated by experienced psychiatrists and diagnosed with persistent ADHD according to DSM-IV (Diagnostic and Statistical Manual for Mental Disorders) criteria. Consensus eligibility criteria for this study across all study sites were a diagnosis of ADHD according to the diagnostic criteria of DSM-IV, onset before the age of 7 years by retrospective diagnosis (which was confirmed by a family member, wherever possible), life-long persistence and current diagnosis. Most controls were screened for the presence of ADHD too (see Supplementary File S1 for more detailed information). All subjects were of Caucasoid origin. Diagnosis was blind to genotype. A detailed description of the samples, instruments, and procedures used by the different sites is provided in Supplementary File S1 and Supplementary Table S1. In total, 1525 patients and 1711 controls are part of IMpACT. Studies were approved by the ethics committees of the participating institutions, and written informed consent was obtained from all patients and controls. Genotyping data for both DAT1 VNTRs were available for 421 patients and 405 controls from IMpACT Germany, for 450 patients and 548 controls from IMpACT Norway, IMpACT Spain contributed 264 patients and 195 controls, and from IMpACT The Netherlands 269 patients and 532 controls with complete genotyping data were available. The total numbers of genotyped cases and controls were 1404 and 1680, respectively (see Table 1).

\section{Genotyping of the Two DAT1 VNTRs}

Genotyping of the $40 \mathrm{bp}$ VNTR located in the $3^{\prime}$-UTR of $D A T 1$ had been carried out earlier at the different IMpACT sites. Procedures and/or references can be found in Supplementary File S1. As part of quality control, all four sites each sent 24 DNA samples to Norway for genotyping of the DAT1 3'-UTR repeat, according to the high-resolution method used in Norway (see Supplementary File S1). Samples were dispensed to one common 96-well plate, and the operator was blinded to the sample ID and country of origin of the samples. Genotyping concordance between tests was $100 \%$ for all 96 samples. The intron 8 VNTR was 
Table I Numbers of Cases and Controls Successfully Genotyped for both VNTRs in DATI

\begin{tabular}{|c|c|c|c|c|}
\hline & Cases & Cases included in analysis & Controls & Controls included in analysis \\
\hline \multicolumn{5}{|c|}{ Samples from the International Multicentre Persistent ADHD CollaboraTion (IMpACT) } \\
\hline Germany & 421 & 406 & 405 & 393 \\
\hline Norway & 450 & 432 & 548 & 530 \\
\hline Spain & 264 & 249 & 195 & 184 \\
\hline Netherlands & 269 & 238 & 532 & 491 \\
\hline Inattentive subtype & $256(19.3 \%)$ & & & \\
\hline Hyperactive/impulsive subtype & $66(5.0 \%)$ & & & \\
\hline Unknown & 75 (5.7\%) & & & \\
\hline \multicolumn{5}{|l|}{ Other samples } \\
\hline & 1520 & 1440 & 1854 & 1769 \\
\hline
\end{tabular}

Only samples with common alleles were included in the analysis. The subtyping data refer to the samples from IMpACT included in the analysis only.

genotyped in The Netherlands (Norwegian, Spanish, and Dutch samples) or Germany according to the protocol used by the Dutch IMpACT partner (see Supplementary File S1).

\section{Statistical Analysis}

Hardy-Weinberg equilibrium (HWE) was assessed for all available samples using the Markov Chain Monte-Carlo approximation of the exact test implemented in the GENEPOP package V 3.3 (Raymond and Rousset, 1995), and genotype distributions were consistent with HWE for both polymorphisms in all four samples $(p>0.01)$. Before haplotype estimation, the VNTRs were recoded, lumping all rare alleles into one group, so that three alleles for the 3 '-UTR VNTR (ie, the 9-repeat and 10-repeat alleles plus a rare alleles pool), and three alleles for the intron 8 VNTR (ie, the 5-repeat and 6-repeat alleles plus a rare alleles pool) were considered. Haplotypes were estimated using the haplo.em function implemented in the haplo.stats package (Schaid et al, 2002), which computes maximum likelihood estimates of haplotype probabilities, together with posterior probabilities of haplotype pairs for each subject. Haplotype frequencies are shown in Table 2 . In the further analysis, we only considered the four most common haplotypes, ie, 10-6, 9-6, 9-5, and 10-5. All haplotypes included in the analysis had a posterior probability of $97 \%$ or higher.

A combined analysis was carried out including the samples of IMpACT only. A trend test was used to evaluate the ADHD risk conferred by carrying the 9-6 haplotype using basic $\chi^{2}$ and logistic regression tests. We focused on the 9-6 haplotype because this had been implicated by one of our earlier studies (Franke et al, 2008). The effect of the 9/9 genotype $v s$ all other genotypes was also tested using a $\chi^{2}$-test. These tests used SPSS (version 16.0).

The meta-analysis examined the haplotype association of the 9-6 allelic combination with the risk of ADHD relative to all other alleles in the entire sample, and in a subsample of patients with combined or hyperactive/impulsive ADHD subtype. In addition, allelic and genotypic ORs were calculated for the two VNTRs, separately, with the most common allele or genotype as the reference.

To combine the individual study results, we conducted meta-analyses using RevMan (version 5.0.2) (The Cochrane Collaboration, 2008). The heterogeneity between studies was tested using the Q-statistic (Lau et al, 1997; Fleiss, 1981). Inconsistency across studies was quantified with the $I^{2}$ metric $\left(I^{2}=\mathrm{Q}-\mathrm{df} / \mathrm{Q}\right)$ (Zintzaras and Hadjigeorgiou, 2004). When no heterogeneity was present, the pooled OR was estimated using fixed effects model (Mantel and Haenzsel, 1959). Otherwise, random effects model (DerSimonian and Laird, 1986) were applied to obtain the pooled OR (Whitehead, 2002). The results of the association tests are indicated as pooled ORs with the corresponding $95 \%$ confidence intervals (CIs) of the haplotype-/allele- or genotype-induced risk of persistent ADHD. $P<0.05$ was considered statistically significant.

\section{RESULTS}

Within the IMpACT group, 1404 persistent ADHD patients and 1680 controls, in which both VNTRs had been genotyped, were considered for inclusion in the study (Table 1). Supplementary Table S2 shows the characteristics of the IMpACT patient samples.

The haplotype frequencies in the different samples are shown in Table 2. Of the total number of patients and controls, we included only those individuals that carried the four most common haplotypes for both VNTRs (ie, those containing the 9-repeat or 10-repeat allele of the $3^{\prime}$-UTR VNTR and the 5-repeat or 6-repeat allele of the intron 8 VNTR). This led to the exclusion of 80 patients and 85 controls (Table 1). Haplotype frequencies varied among countries, with the 9-6 allele being more frequent in the 
Table 2 Frequencies of Haplotypes per Country (Haplotypes Coded as 'Other' Consist of a Mixture of Rare Haplotypes)

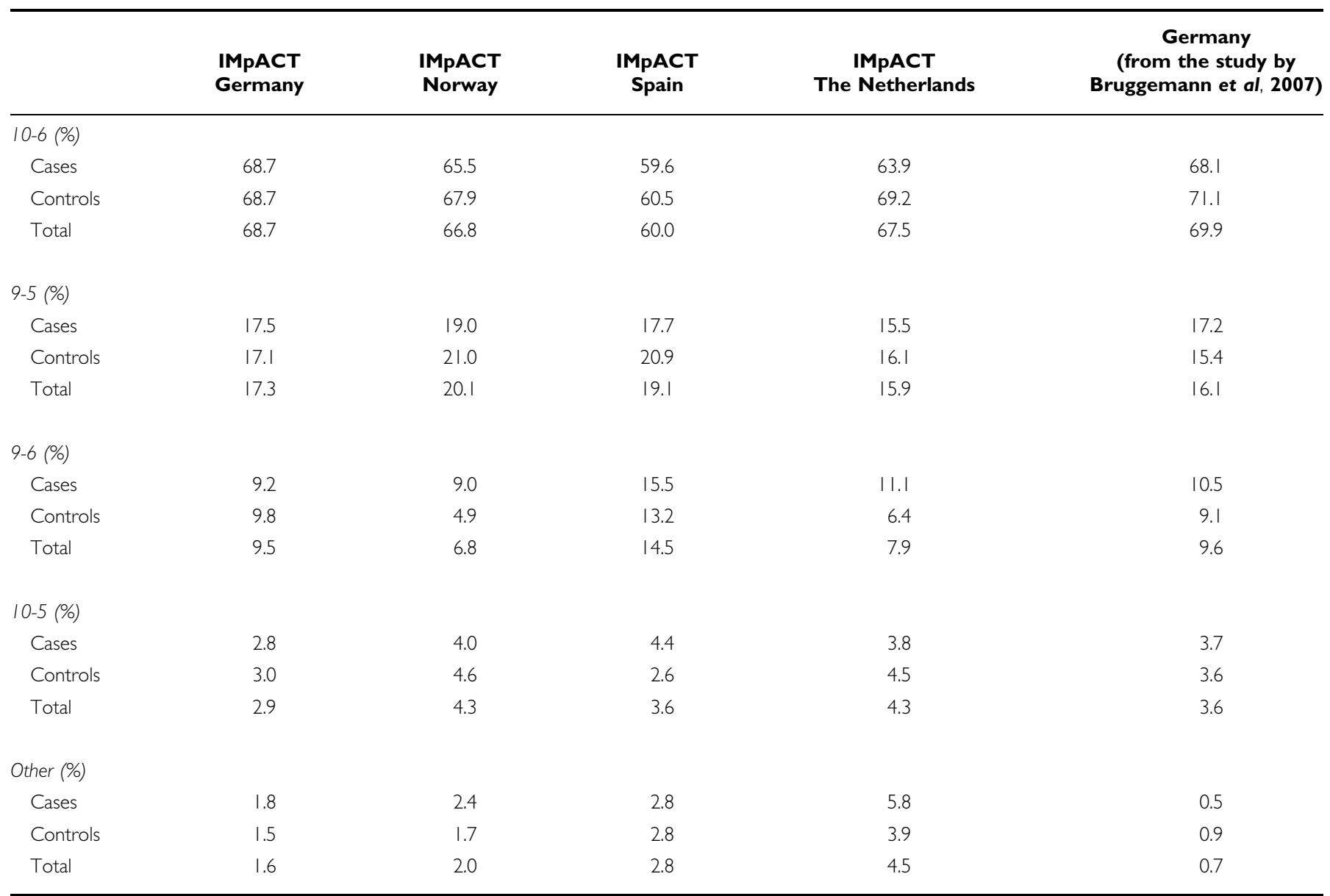

Table 3 Analysis of the Association of the 9-6 Haplotype Formed by the 3'-UTR and Intron 8 VNTRs of the SLC6A3 Gene vs all Other (frequent) Haplotypes

\begin{tabular}{|c|c|c|c|c|c|}
\hline \multirow{2}{*}{ Number of $9-6$ alleles } & \multicolumn{2}{|c|}{ Frequency (\%) } & \multirow[b]{2}{*}{ Pearson's $\chi^{2} p$-value ${ }^{a}$} & \multirow[b]{2}{*}{$\mathbf{O R}^{\mathbf{b}}$} & \multirow[b]{2}{*}{$95 \% \mathrm{Cl}$} \\
\hline & Controls & Cases & & & \\
\hline । & $221(13.8)$ & $244(18.4)$ & & & \\
\hline 2 & $7(0.4)$ & $19(1.4)$ & & & \\
\hline
\end{tabular}

${ }^{\mathrm{a}} \mathrm{df}=2$.

bogistic regression analysis.

Spanish sample compared with the other Northern European samples (Table 2).

We first performed a combined analysis in the IMpACT sample only. In a sample of 1325 patients and 1598 controls, we evaluated if there was a difference in the distribution of the 9-6 haplotype between cases and controls. As shown in Table 3, this haplotype indeed was significantly more frequent in the cases $\left(\chi^{2}=20.36 ; \mathrm{df}=2 ; p<0.001\right)$. The allelic trend test showed a risk increase of 1.5 (95\% CI 1.25-1.79) for carrying a 9-6 haplotype. Interestingly, an analysis of the $9 / 9$ genotype $v s$ all other genotypes showed essentially the same result $(9 / 9$ homozygotes $=99(6.2 \%)$ in controls and $119(9.0 \%)$ in cases; $\chi^{2}=8.15 ; \mathrm{df}=1 ; p=0.005 ; \mathrm{OR}=1.5$, 95\% CI 1.13-1.97).

Given the differences in haplotype frequencies between samples (Table 2), we considered a meta-analysis design more appropriate than a combined analysis for further analysis. In addition to the IMpACT samples, we also 
included data from another published report on the DAT1 VNTR haplotype in adults (Bruggemann et al, 2007) into this meta-analysis, which increased the total number of genotypes included further to 1440 patients with adult ADHD and 1769 controls. Meta-analysis of the data using a random effects model showed that the 9-6 haplotype was significantly associated with ADHD in adults, with an OR of 1.39 (95\% CI 1.03-1.88), $p=0.03$ (Figure 1). As DAT1 has been suggested to be more relevant for those ADHD subtypes including hyperactivity (Diamond, 2007), we repeated the analysis excluding patients with inattentive subtype ADHD from the four IMpACT samples (see Table 1 for the numbers of samples included). As shown in Figure 2, the point estimate for the $\mathrm{OR}$ increased somewhat numerically, but nonsignificantly (OR 1.47, 95\% CI 1.022.12).

We also analyzed the two VNTRs, separately, in the samples included in the haplotype analysis. For the VNTR in the DAT1 3'-UTR the homozygous 10/10 genotype, which is thought to be the risk factor for ADHD in children, did not show association with ADHD in adults (OR $=0.93,95 \%$ CI 0.93-1.07) (Figure 3a). However, as in the combined analysis, we did observe an association of the homozygous 9/9 genotype with persistent ADHD (Figure 3b), with an effect size similar to the one observed for the 9-6 haplotype (OR 1.34, 95\% CI 1.03-1.76), $p=0.03$. The intron 8 VNTR by itself did not have any effect on ADHD risk in the adults (Supplementary Figure S1A-C).

\section{DISCUSSION}

In this study we investigated two VNTRs within the SLC6A3/DAT1 gene and the haplotypes formed by them for association with persistent ADHD. The study included genotype information on 1440 patients, of whom 1100 were formerly unpublished ones from the IMpACT study group. Both the 9-6 haplotype (3'-UTR VNTR/Intron 8 VNTR) and the 9/9 genotype of the $3^{\prime}$-UTR VNTR showed association with the disorder in adults using two different analysis methods, ie, a combined analysis and a meta-analysis design. The intron 8 VNTR by itself did not seem to increase persistent ADHD risk.

The two VNTRs within SLC6A3/DAT1 have both been suggested to influence the regulation of the gene (Brookes et al, 2007; Spencer et al, 2005; Guinda-Lini et al, 2006). However, in vivo and in vitro studies for the 3'-UTR VNTR have not been consistent, and the intron 8 VNTR has so far only been studied once. It might therefore also be possible that - instead of being directly involved in regulating gene expression - both VNTRs (incompletely) tag an unknown functional site, with the haplotype increasing the efficiency of the tagging (Asherson et al, 2007).

The finding of association with persistent ADHD for the 9-6 haplotype supports an earlier report in the Dutch IMpACT subsample (Franke et al, 2008). This finding, as well as the finding that the $9 / 93^{\prime}$-UTR VNTR genotype is associated with persistent ADHD, is contrary to findings in
Cases

Controls

Study or Subgroup

Germany, Brüggemann et
Germany, unpublished
Netherlands, Franke et al
Norway, unpublished
Spain, unpublished

Total $(95 \% \mathrm{Cl})$

Total events

Heterogeneity: $\mathrm{Tau}^{2}=0.08 ; \mathrm{Chi}^{2}=11.60, \mathrm{df}=4(\mathrm{P}=0.02) ; \mathrm{I}^{2}=66 \%$

Test for overall effect: $Z=2.13(P=0.03)$
Controls Odds Ratio

M-H, Random, 95\% Cl

$1.17[0.67,2.05]$

$0.95[0.68,1.33]$

$1.93[1.31,2.84]$

$1.94[1.34,2.79]$

$1.22[0.83,1.80]$

$1.39[1.03,1.88]$

Figure I Forest plot showing the analysis of the 9-6 VNTR haplotype vs all other haplotypes.

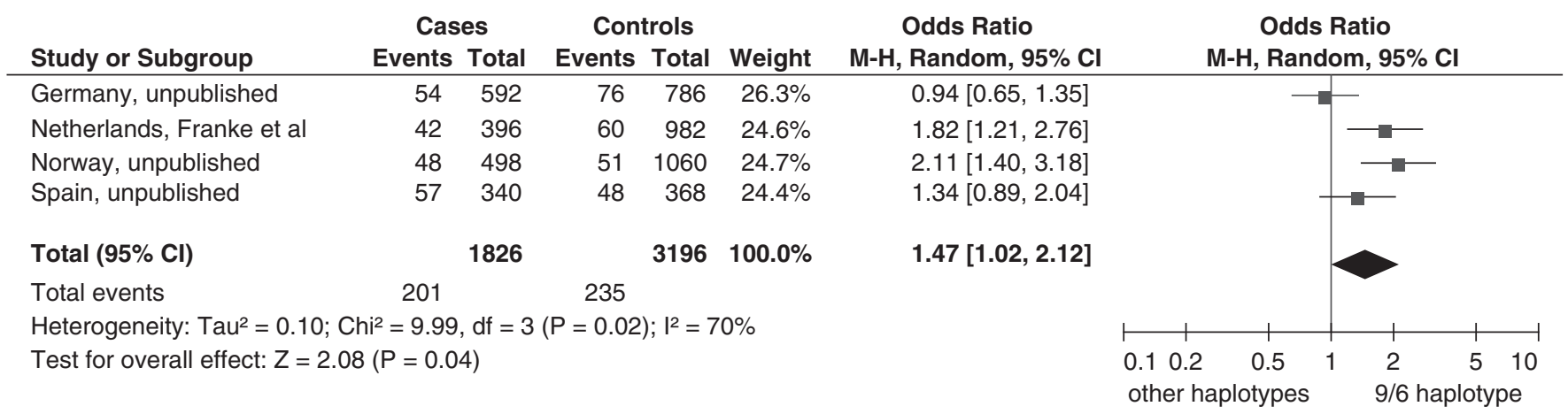

Figure 2 Forest plot showing the analysis of the 9-6 haplotype vs all others for patients with ADHD subtypes containing hyperactivity (combined subtype and hyperactive/impulsive subtype) only. 
a

\begin{tabular}{lrrrrr} 
Study or Subgroup & Events & Total & Events & Total & Weight \\
\hline Germany, Brüggemann et al & 57 & 105 & 97 & 170 & $8.5 \%$ \\
Germany, unpublished & 213 & 406 & 201 & 393 & $24.4 \%$ \\
Netherlands, Franke et al & 120 & 238 & 283 & 491 & $23.0 \%$ \\
Norway, unpublished & 220 & 432 & 277 & 530 & $30.7 \%$ \\
Spain, unpublished & 113 & 249 & 85 & 184 & $13.4 \%$ \\
& & & & & \\
Total $(95 \%$ Cl) & & 1430 & & 1768 & $100.0 \%$ \\
Total events & 723 & 943 & & \\
Heterogeneity: Chi $^{2}=2.77$, df $=4(P=0.60) ;\left.\right|^{2}=0 \%$ & & &
\end{tabular}

Odds Ratio Odds Ratio

M-H, Fixed, 95\% Cl

$0.89[0.55,1.46]$

$1.05[0.80,1.39]$

$0.75[0.55,1.02]$

$0.95[0.74,1.22]$

$0.97[0.66,1.42]$

$0.93[0.80,1.07]$

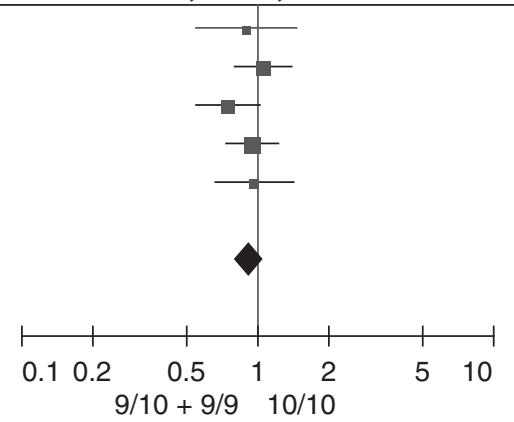

\begin{tabular}{|c|c|c|c|c|c|c|c|c|c|c|}
\hline \multirow{2}{*}{$\begin{array}{l}\text { b } \\
\text { Study or Subgroup }\end{array}$} & \multicolumn{2}{|c|}{ cases } & \multicolumn{2}{|c|}{ controls } & \multirow[b]{2}{*}{ Weight } & \multirow{2}{*}{$\begin{array}{c}\text { Odds Ratio } \\
\text { M-H, Fixed, } 95 \% \mathrm{Cl}\end{array}$} & \multirow{2}{*}{\multicolumn{4}{|c|}{$\begin{array}{c}\text { Odds Ratio } \\
\text { M-H, Fixed, } 95 \% \mathrm{Cl}\end{array}$}} \\
\hline & Events & Total & Events & Total & & & & & & \\
\hline Germany, Brüggemann et al & 9 & 115 & 11 & 171 & $8.9 \%$ & $1.23[0.49,3.08]$ & & & - & \\
\hline Germany, unpublished & 27 & 406 & 22 & 393 & $22.7 \%$ & $1.20[0.67,2.15]$ & & & & \\
\hline Netherlands, Franke et al & 18 & 238 & 22 & 491 & $14.4 \%$ & $1.74[0.92,3.32]$ & & & - & \\
\hline Norway, unpublished & 38 & 432 & 26 & 530 & $23.1 \%$ & $1.87[1.12,3.13]$ & & & -6 & \\
\hline Spain, unpublished & 36 & 249 & 29 & 184 & $31.0 \%$ & $0.90[0.53,1.54]$ & & & & \\
\hline Total $(95 \% \mathrm{Cl})$ & & 1440 & & 1769 & $100.0 \%$ & $1.34[1.03,1.76]$ & & & & \\
\hline Total events & 128 & & 110 & & & & & & & \\
\hline \multicolumn{7}{|c|}{ Heterogeneity: $\mathrm{Chi}^{2}=4.53, \mathrm{df}=4(\mathrm{P}=0.34) ; \mathrm{I}^{2}=12 \%$} & & & & \\
\hline \multicolumn{7}{|c|}{ Test for overall effect: $Z=2.17(P=0.03)$} & $\begin{array}{r}0.10 .2 \\
9 / 10\end{array}$ & $\begin{array}{c}0.5 \\
+10 / 10\end{array}$ & $\begin{array}{ll}1 & 2 \\
9 / 9\end{array}$ & 510 \\
\hline
\end{tabular}

Figure 3 (a) Forest plot showing the analysis of the DATI 3'-UTR VNTR I0/I0 genotype vs all other genotypes. (b) Forest plot showing the analysis of the DATI 3'-UTR VNTR 9/9 genotype vs all other genotypes.

children with ADHD, where the 10-6 haplotype and the 10/10 genotype have been suggested to be risk factors for the disorder (Brookes et al, 2006; Asherson et al, 2007; Faraone et al, 2005). This is not likely to reflect a mere population-specific effect, as the populations represented in this adult study are also represented (apart from the Norwegian sample) in the studies showing the effects of the 10-6 haplotype (eg, in the IMAGE study; Asherson et al, 2007). A major difference between most samples of childhood and adult ADHD is the gender distribution. Although in children the male to female ratio lies between $3: 1$ and 9:1 (Staller and Faraone, 2006), the gender distribution is much more equal in adults with ADHD (Kessler et al, 2006). However, it is unlikely that gender causes the differences in the findings for children and adults, as a male-specific analysis in this study did not change the results presented here (not shown). Another difference between samples of children and adults may be the comorbidity profile. Although comorbidity is the rule rather than the exception in both groups of patients, the prevalence of specific comorbid disorders may differ. This issue is further discussed below.

Despite an impressive number of studies already performed, the role of DAT1 in ADHD, even in children, is still far from clear. The $3^{\prime}$-UTR VNTR has been investigated in multiple studies, but meta-analyses of the genotyping data are controversial (Maher et al, 2002; Faraone et al, 2005; Todd et al, 2005; Yang et al, 2007; Li et al, 2006). The same holds true for the current findings: although our metaanalysis included 1440 patients and 1854 controls, the $p$-values we report are only nominally significant (we did not carry out correction for multiple testing for the correlated tests). Hence, for both children and adults, the evidence for an association of the DAT1 gene with ADHD is still far from reaching genome-wide significance. Apart from the possibility that the gene is simply not associated with ADHD after all, additional explanations for the limited significance of the findings are as follows: first, only a subgroup of patients might show the association with the gene. For example, data from studies by Diamond (2007) suggest that DAT1 has a more important role in ADHD subtypes featuring hyperactivity symptoms than in the inattentive subtype. In this study, we did not find evidence to support this hypothesis. Also, DAT1 might be linked to ADHD only in the absence or presence of a given comorbidity. This hypothesis recently found some support from the work within the IMAGE study, in which Zhou et al (2008) showed that DAT1 was only associated with ADHD in children without comorbid conduct problems. This possibility needs to be tested in future studies. A second possible explanation, as mentioned above, is that the VNTRs and their haplotype incompletely tag the real ADHD risk variant in $D A T 1$, or that additionally, other variants in or near the gene also exert an effect on ADHD risk. The latter view is again supported by the IMAGE study, which suggests that two different loci within DAT1, one $5^{\prime}$ and one $3^{\prime}$ site, influence ADHD risk in children (Brookes et al, 2008). As most studies up to now have studied children with the disorder, a third possible explanation is that age is an important factor to take into account when studying the role of DAT1 in ADHD. 
The putative differential association of DAT1 with ADHD in children and adults might arise from different causes. Possibly, the 9/9 3'-UTR VNTR genotype and/or the 9-6 haplotype predispose(s) to a more severe ADHD phenotype characterized by persistence into adulthood. As only a subgroup of children with ADHD remit (Faraone et al, 2006; Barkley et al, 2006a; Kessler et al, 2005b), this subgroup might not be equally represented in all association studies of childhood ADHD. Some support for this hypothesis is provided by a prospective 13-year follow-up study indicating that more ADHD symptoms and externalizing behaviors were present in the $9 / 10$ than in the $10 / 10$ genotype for the group as a whole, and that the effects of the genotype became more pronounced with increasing age of the participants. Importantly, more individuals with a DSM diagnosis of ADHD in adulthood were found among those having the $9 / 10$ genotype (53\%) than among the 10/10 homozygous group (35\%) (Barkley et al, 2006b). On the other hand, as dopamine transporter density decreases during life (Spencer et al, 2005) and ADHD symptoms are known to change during adolescence (Biederman et al, 2000), the differential association of DAT1 with ADHD might reflect changing requirements on the dopaminergic system during life. Furthermore, adults more often than children consume cigarettes, alcohol or drugs, environmental factors that are known to influence the regulation of the dopamine transporter (Madras et al, 2005). An additional potential explanation might be that DAT1 genotype effects on ADHD depend on the effect of another gene, which shows development-specific association with ADHD. A good candidate for this is COMT, encoding the catechol-Omethyltransferase, a major contributor to (prefrontal cortex) dopaminergic metabolism. Several recent studies suggest a double dissociation of dopamine effects, depending on COMT and DAT1 genotype in dopaminerelated brain activity (Bertolino et al, 2008; Yacubian et al, 2007). However, an involvement of COMT in ADHD has been suggested for both children and adults (eg, LaskySu et al, 2008; Halleland et al, 2008). Future studies of the DAT1 VNTR haplotype might want to use brain imaging to investigate the neural substrates of the differences between children and adults. One would predict that these substrates are different for the different developmental stages. However, as this study is crosssectional we cannot exclude the possibility that individuals seeking treatment as children are different from those seeking treatment as adults. This might be suggested by findings of other phenotypes associated with DAT1, such as decreased delinquency and promiscuous behavior in teenagers with the 9/9 genotype of the $3^{\prime}$-UTR VNTR (Guo et al, 2007).

In conclusion, our data bear the intriguing suggestion that the DAT1 haplotype and genotype associated with ADHD in adults might be different from the one associated with the childhood disorder. A differential association of the DAT1 gene with ADHD in children and in adults might help to explain the inconsistencies observed in association studies, where age is not commonly taken into account. However, the data might also imply that the gene has a role in modulating the ADHD phenotype, rather than causing it.

\section{ACKNOWLEDGEMENTS}

We are grateful to all patients and controls for their participation in the study. We thank Pål Borge and Sigrid Erdal for help with genotyping of the Norwegian samples. We thank Mariana Nogueira and Montse Corrales for their involvement in the clinical assessment and Lucas Brunso for his contribution to the genotyping in Spain. We thank Remco Makkinje and Marlies Naber for help with genotyping in The Netherlands. The Dutch controls were derived from the Nijmegen Biomedical Study. Principal investigators of the Nijmegen Biomedical Study are LALM Kiemeney, M den Heijer, ALM Verbeek, DW Swinkels, and B Franke. We thank Dr Marcella Rietschel, Dr Esther Sobanski, and Dr Josef Frank for providing us with the DAT1 genotype information from their study. The Norwegian part of the study was sponsored by Research Council of Norway. Financial support for the Spanish part of the study was received from 'Instituto de Salud Carlos III-FIS, Spain' (PI040524, PI041267) and 'Agència de Gestió d'Ajuts Universitaris i de Recerca-AGAUR' (2005SGR00848). $M B$ and MR are recipients of a 'Ramon y Cajal' and a 'Juan de la Cierva' contract, respectively, from 'Ministerio de Ciencia y Tecnología' (Spain). The Dutch part of the project was supported by the Hersenstichting Nederland (Fonds Psychische Gezondheid).

\section{DISCLOSURE}

The authors declare no conflict of interest.

\section{REFERENCES}

Asherson P, Brookes K, Franke B, Chen W, Gill M, Ebstein RP et al (2007). Confirmation that a specific haplotype of the dopamine transporter gene is associated with combined-type ADHD. Am J Psychiatry 164: 674-677.

Barkley RA, Fischer M, Smallish L, Fletcher K (2006a). Young adult outcome of hyperactive children: adaptive functioning in major life activities. J Am Acad Child Adolesc Psychiatry 45: 192-202.

Barkley RA, Smith KM, Fischer M, Navia B (2006b). An examination of the behavioral and neuropsychological correlates of three ADHD candidate gene polymorphisms (DRD4 7+, DBH TaqI A2, and DAT1 $40 \mathrm{bp}$ VNTR) in hyperactive and normal children followed to adulthood. Am J Med Genet B Neuropsychiatr Genet 141: 487-498.

Bernfort L, Nordfeldt S, Persson J (2008). ADHD from a socioeconomic perspective. Acta Paediatr 97: 239-245.

Bertolino A, Di GA, Blasi G, Sambataro F, Caforio G, Sinibaldi L et al (2008). Epistasis between dopamine regulating genes identifies a nonlinear response of the human hippocampus during memory tasks. Biol Psychiatry 64: 226-234.

Biederman J, Mick E, Faraone SV (2000). Age-dependent decline of symptoms of attention deficit hyperactivity disorder: impact of remission definition and symptom type. Am J Psychiatry 157: 816-818.

Brookes KJ, Mill J, Guindalini C, Curran S, Xu X, Knight J et al (2006). A common haplotype of the dopamine transporter gene associated with attention-deficit/hyperactivity disorder and interacting with maternal use of alcohol during pregnancy. Arch Gen Psychiatry 63: 74-81. 
Brookes KJ, Neale BM, Sugden K, Khan N, Asherson P, D'Souza UM (2007). Relationship between VNTR polymorphisms of the human dopamine transporter gene and expression in postmortem midbrain tissue. Am J Med Genet B Neuropsychiatr Genet 144B: 1070-1078.

Brookes KJ, Xu X, Anney R, Franke B, Zhou K, Chen W et al (2008). Association of ADHD with genetic variants in the $5^{\prime}$-region of the dopamine transporter gene: evidence for allelic heterogeneity. Am J Med Genet B Neuropsychiatr Genet 147B: 1519-1523.

Bruggemann D, Sobanski E, Alm B, Schubert T, Schmalzried H, Philipsen A et al (2007). No association between a common haplotype of the 6 and 10-repeat alleles in intron 8 and the $3^{\prime}$ UTR of the DAT1 gene and adult attention deficit hyperactivity disorder. Psychiatr Genet 17: 121.

Cook Jr EH, Stein MA, Krasowski MD, Cox NJ, Olkon DM, Kieffer JE et al (1995). Association of attention-deficit disorder and the dopamine transporter gene. Am J Hum Genet 56: 993-998.

DerSimonian R, Laird N (1986). Meta-analysis in clinical trials. Control Clin Trials 7: 177-188.

Diamond A (2007). Consequences of variations in genes that affect dopamine in prefrontal cortex. Cereb Cortex 17(Suppl 1): i161-i170.

Faraone SV (2002). Report from the third international meeting of the Attention-Deficit Hyperactivity Disorder Molecular Genetics Network. Am J Med Genet 114: 272-276.

Faraone SV (2003). Report from the 4th international meeting of the attention deficit hyperactivity disorder molecular genetics network. Am J Med Genet B Neuropsychiatr Genet 121: $55-59$.

Faraone SV (2004). Genetics of adult attention-deficit/hyperactivity disorder. Psychiatr Clin North Am 27: 303-321.

Faraone SV, Biederman J, Mick E (2006). The age-dependent decline of attention deficit hyperactivity disorder: a metaanalysis of follow-up studies. Psychol Med 36: 159-165.

Faraone SV, Biederman J, Spencer T, Wilens T, Seidman LJ, Mick E et al (2000). Attention-deficit/hyperactivity disorder in adults: an overview. Biol Psychiatry 48: 9-20.

Faraone SV, Perlis RH, Doyle AE, Smoller JW, Goralnick JJ, Holmgren MA et al (2005). Molecular genetics of attentiondeficit/hyperactivity disorder. Biol Psychiatry 57: 1313-1323.

Faraone SV, Spencer T, Aleardi M, Pagano C, Biederman J (2004). Meta-analysis of the efficacy of methylphenidate for treating adult attention-deficit/hyperactivity disorder. J Clin Psychopharmacol 24: 24-29.

Fleiss J (1981). Statistical Methods for Rates and Proportions. In. Wiley: New York.

Franke B, Hoogman M, Arias VA, Heister JG, Savelkoul PJ, Naber $\mathrm{M}$ et al (2008). Association of the dopamine transporter (SLC6A3/DAT1) gene 9-6 haplotype with adult ADHD. Am J Med Genet B Neuropsychiatr Genet 147B: 1576-1579.

Goodman DW (2007). The consequences of attentiondeficit/hyperactivity disorder in adults. J Psychiatr Pract 13: 318-327.

Guindalini C, Howard M, Haddley K, Laranjeira R, Collier D, Ammar N, et al (2006). A dopamine transporter gene functional variant associated with cocaine abuse in a Brazilian sample. Proc Natl Acad Sci USA 103: 4552-4557

Guo G, Roettger ME, Shih JC (2007). Contributions of the DAT1 and DRD2 genes to serious and violent delinquency among adolescents and young adults. Hum Genet 121: 125-136.

Halleland H, Lundervold AJ, Halmoy A, Haavik J, Johansson S (2008). Association between Catechol O-methyltransferase (COMT) haplotypes and severity of hyperactivity symptoms in Adults. Am J Med Genet B Neuropsychiatr Genet 150B: 403-410.

Kessler RC, Adler L, Ames M, Barkley RA, Birnbaum H, Greenberg $\mathrm{P}$ et al (2005a). The prevalence and effects of adult attention deficit/hyperactivity disorder on work performance in a nationally representative sample of workers. J Occup Environ Med 47: 565-572.

Kessler RC, Adler L, Barkley R, Biederman J, Conners CK, Demler $\mathrm{O}$ et al (2006). The prevalence and correlates of adult ADHD in the United States: results from the National Comorbidity Survey Replication. Am J Psychiatry 163: 716-723.

Kessler RC, Adler LA, Barkley R, Biederman J, Conners CK, Faraone SV et al (2005b). Patterns and predictors of attentiondeficit/hyperactivity disorder persistence into adulthood: results from the national comorbidity survey replication. Biol Psychiatry 57: 1442-1451.

Kooij JJ, Buitelaar JK, van den Oord EJ, Furer JW, Rijnders CA, Hodiamont PP (2005). Internal and external validity of attention-deficit hyperactivity disorder in a population-based sample of adults. Psychol Med 35: 817-827.

Lasky-Su J, Neale BM, Franke B, Anney RJ, Zhou K, Maller JB et al (2008). Genome-wide association scan of quantitative traits for attention deficit hyperactivity disorder identifies novel associations and confirms candidate gene associations. Am J Med Genet B Neuropsychiatr Genet 147B: 1345-1354.

Lau J, Ioannidis JP, Schmid CH (1997). Quantitative synthesis in systematic reviews. Ann Intern Med 127: 820-826.

Li D, Sham PC, Owen MJ, He L (2006). Meta-analysis shows significant association between dopamine system genes and attention deficit hyperactivity disorder (ADHD). Hum Mol Genet 15: 2276-2284.

Madras BK, Miller GM, Fischman AJ (2005). The dopamine transporter and attention-deficit/hyperactivity disorder. Biol Psychiatry 57: 1397-1409.

Maher BS, Marazita ML, Ferrell RE, Vanyukov MM (2002). Dopamine system genes and attention deficit hyperactivity disorder: a meta-analysis. Psychiatr Genet 12: 207-215.

Mantel N, Haenzsel W (1959). Statistical aspects of the analysis of data from retrospective studies of disease. J Natl Cancer Inst 22: 719-748.

Medori R, Ramos-Quiroga JA, Casas M, Kooij JJ, Niemela A, Trott GE et al (2008). A randomized, placebo-controlled trial of three fixed dosages of prolonged-release OROS methylphenidate in adults with attention-deficit/hyperactivity disorder. Biol Psychiatry 63: 981-989.

Polanczyk G, de Lima MS, Horta BL, Biederman J, Rohde LA (2007). The worldwide prevalence of ADHD: a systematic review and metaregression analysis. Am J Psychiatry 164: 942-948.

Raymond M, Rousset F (1995). GENEPOP (Version 1.2): population genetics software for exact tests and ecumenicism. J Heredity 86: 248-249.

Schaid DJ, Rowland CM, Tines DE, Jacobson RM, Poland GA (2002). Score tests for association between traits and haplotypes when linkage phase is ambiguous. Am J Hum Genet 70: 425-434.

Spencer TJ, Biederman J, Madras BK, Faraone SV, Dougherty DD, Bonab AA et al (2005). In vivo neuroreceptor imaging in attention-deficit/hyperactivity disorder: a focus on the dopamine transporter. Biol Psychiatry 57: 1293-1300.

Staller J, Faraone SV (2006). Attention-deficit hyperactivity disorder in girls: epidemiology and management. CNS Drugs 20: $107-123$.

The Cochrane Collaboration (2008). Review Manager (RevMan). In. The Nordic Cochrane Centre: Copenhagen.

Todd RD, Huang H, Smalley SL, Nelson SF, Willcutt EG, Pennington $\mathrm{BF}$ et al (2005). Collaborative analysis of DRD4 and DAT genotypes in population-defined ADHD subtypes. J Child Psychol Psychiatry 46: 1067-1073.

Whitehead A (2002). Dealing with Heterogeneity. In. Whiley: Chicester. pp 151-174.

Yacubian J, Sommer T, Schroeder K, Glascher J, Kalisch R, Leuenberger B et al (2007). Gene-gene interaction associated 
with neural reward sensitivity. Proc Natl Acad Sci USA 104: 8125-8130.

Yang B, Chan RC, Jing J, Li T, Sham P, Chen RY (2007). A metaanalysis of association studies between the 10-repeat allele of a VNTR polymorphism in the $3^{\prime}$-UTR of dopamine transporter gene and attention deficit hyperactivity disorder. Am J Med Genet B Neuropsychiatr Genet 144: 541-550.
Zhou K, Chen W, Buitelaar J, Banaschewski T, Oades RD, Franke B et al (2008). Genetic heterogeneity in ADHD: DAT1 gene only affects probands without CD. Am J Med Genet B Neuropsychiatr Genet 147B: 1481-1487.

Zintzaras E, Hadjigeorgiou GM (2004). Association of paraoxonase 1 gene polymorphisms with risk of Parkinson's disease: a metaanalysis. J Hum Genet 49: 474-481.

Supplementary Information accompanies the paper on the Neuropsychopharmacology website (http://www.nature.com/npp) 